\title{
Pleasure-Related Analgesia Activates Opioid-Insensitive Circuits
}

\author{
Elvan Kut, ${ }^{1}$ Victor Candia, ${ }^{1}$ Jan von Overbeck, ${ }^{2}$ Judit Pok, ${ }^{3}$ Daniel Fink, ${ }^{3}$ and Gerd Folkers ${ }^{1}$ \\ ${ }^{1}$ Collegium Helveticum, University of Zurich and ETH Zurich, 8092 Zurich, Switzerland, ${ }^{2}$ Swiss Center for Telemedicine Medgate, 4020 Basel, Switzerland, \\ and ${ }^{3}$ Department of Obstetrics and Gynecology, University Hospital of Zurich, 8091 Zurich, Switzerland
}

Recent findings suggest that pain and pleasure share common neurochemical circuits, and studies in animals and humans show that opioid-mediated descending pathways can inhibit or facilitate pain. We explored the role of endogenous opioid neurotransmission in pleasure-related analgesia. $\mu$-0pioidergic activity was blocked with $0.2 \mathrm{mg} / \mathrm{kg}$ naloxone to assess its effects on hedonic responses to pleasant emotional pictures (International Affective Picture System) and its modulating effects on heat pain tolerance. Naloxone did not alter subjective and autonomous reactions to pleasure induction or overall mood of participants. In addition, pleasure-related increases in pain tolerance persisted after reversal of endogenous $\mu$-opioidergic neurotransmission. Subjective pain intensity and unpleasantness ratings increased after naloxone administration. These findings suggest that, in addition to opioid-sensitive circuits, mainly opioidinsensitive pain-modulating circuits are activated during pleasure-related analgesia.

\section{Introduction}

Pain and pleasure appear to be at opposite ends of a single scale (Leknes and Tracey, 2008). However, we often experience situations where both sensations are intertwined. For example, pain can enhance pleasure while eating spicy food (Rozin and Schiller, 1980). Also, positive affective states decrease pain perception (de Wied and Verbaten, 2001; Meagher et al., 2001; Rainville et al., 2005; Kut et al., 2007; Lewkowski et al., 2008; Roy et al., 2009; Villemure and Bushnell, 2009). Yet the neural underpinnings of pleasure-related analgesia have hardly been explored and clearly deserve more attention.

Recent studies in animals and humans show that an opioidmediated descending pain system can inhibit or facilitate pain (Fields, 2004). Altered $\mu$-opioid receptor availability has been found in brain regions thought to be mainly involved in mediating the affective components of pain (Zubieta et al., 2001; Sprenger et al., 2006). Moreover, there is important evidence on the involvement of $\mu$-opioid neurotransmission in attentional and cognitive modulation (e.g., placebo effect) of pain (Benedetti et al., 2005; Tracey and Mantyh, 2007; Enck et al., 2008; Wiech et al., 2008). Pain modulation by means of context, expectancy, or attention is regulated, at least in part, by descending and opioidsensitive modulatory circuits (Petrovic et al., 2002; Colloca and Benedetti, 2005) and, in addition, by the direct effects of opioids

\footnotetext{
Received July 19, 2010; revised Dec. 16, 2010; accepted Jan. 21, 2011.

This work was supported by the University of Zurich, the ETH Zurich, and a grant from the Cogito Foundation. We thank Peter Krummenacher, Amrei Wittwer, Nils Schaffner, Georg Schönbächler, Roseline Porchet, and Jair Stern from the Collegium Helveticum; Dana Briegel, Meike Brockmann, and the staff at the Department of Gynecology of the University Hospital Zurich; and Andreas Keil from the University of Florida for valuable help.

The authors declare no competing financial interest.

Correspondence should be addressed to Dr. Elvan Kut, Collegium Helveticum, University of Zurich and ETH Zurich, Schmelzbergstrasse 25, 8092 Zurich, Switzerland. E-mail: kut@collegium.ethz.ch.

DOI:10.1523/JNEUROSCI.3736-10.2011

Copyright $\odot 2011$ the authors $\quad 0270-6474 / 11 / 314148-06 \$ 15.00 / 0$
}

upon cortical nociceptive-related areas (e.g., anterior cingulate cortex) (Petrovic et al., 2002).

The mood-elevating effects of opiates have been known and used for millennia. After comprehensive research in mice (Panksepp, 2003; Burgdorf and Panksepp, 2006; Fields, 2007), increasingly, imaging studies are examining the involvement of opioidergic neurotransmission in the regulation of affective states in humans. For example, whereas sustained sadness was associated with a deactivation in $\mu$-opioid neurotransmission (Zubieta et al., 2003), euphoric mood states were inversely correlated with opioid binding in prefrontal/orbitofrontal cortices (Boecker et al., 2008). Moreover, opioids seem to be implicated in the hedonic response to pleasant sensory and emotional stimuli, such as sweet taste (Berridge, 2003; Peciña, 2008) or visual stimuli (Gospic et al., 2008).

Until now, investigations have mostly explored the role of opioid neurotransmission in both phenomena in isolation but not in their interaction (Leknes and Tracey, 2008). Recently, it has been shown that naloxone blocking of the pain-inhibitory circuit involving opioid-rich areas enhances the acquisition of conditioned fear in humans to brief pain stimuli of the kind we have used here (Eippert et al., 2008). In addition, a general circuit bridging pain and reward networks has been suggested for the processing of aversive and rewarding information (Becerra et al., 2001). Bearing this in mind, we hypothesized that pleasant affective states will be associated with enhanced opioidergic neurotransmission, contributing to reduced pain perception. Further, we hypothesized that mood-elevating pictures would alter pain intensity and unpleasantness. To assess the effects of endogenous opioids upon pleasure-related analgesia, we used naloxone, a predominantly $\mu$-opioid-receptor antagonist that temporarily reverses the effects of $\mu$-opioidergic activity (Amanzio and Benedetti, 1999). We investigated whether the reversal of $\mu$-opioidergic activity by means of naloxone can attenuate the hedonic response to pleas- 
ant emotional pictures [International Affective Picture System (IAPS)] and reduce pleasure-related analgesia. In particular, we analyzed the effects of naloxone during pleasure induction on heat pain tolerance, subjective pain intensity and unpleasantness, self-reports on valence and arousal of experienced affective states, autonomic reactions (startle magnitude and skin conductance level) and overall mood.

\section{Materials and Methods}

Participants. Twenty-two healthy right-handed male volunteers (mean age, 26.5 years; range, 19-44) were included in the study. All participants had normal pain thresholds at the site of stimulus application (Yarnitsky et al., 1995; Schaffner et al., 2008), no history of neurological or psychiatric disease or drug abuse, no history of chronic or acute pain, and were not taking any form of analgesic, antidepressant, anti-anxiety or antihypertensive medication. Participants were asked to refrain from alcoholic beverages $12 \mathrm{~h}$ before the experiment. Handedness was determined using a standard handedness inventory (Chapman and Chapman, 1987). The study was conducted in accordance with the Declaration of Helsinki on the treatment of human subjects and was approved by the local research ethics committee and federal authorities. All participants gave written informed consent before participating in the study and were free to withdraw from the study at any time. They were instructed about the doubleblind administration of naloxone and informed that no side effects were expected at the doses used. In addition, participants were told that the administered substance could increase, decrease, or not alter pain perception.

Drug administration. Participants were randomly assigned in a doubleblind manner to either a naloxone or a control group. An intravenous catheter was placed in the antecubital vein of the nondominant arm at the beginning of the experimental session. In between blocks, participants in the naloxone group were administered naloxone hydrochloride $(0.2 \mathrm{mg} /$ $\mathrm{kg}$; concentration $1 \mathrm{mg} / \mathrm{ml}$ ) and subjects in the control group an equivalent volume of saline $(0.9 \% \mathrm{NaCl})$. Similar naloxone dosages have been previously shown to completely antagonize endogenous opioid-mediated analgesia in healthy volunteers (Amanzio and Benedetti, 1999).

Emotional stimuli. We used a standardized selection of highly pleasant emotional stimuli from the IAPS (Lang et al., 2004). These pictures have been shown to robustly induce positive affective states and pleasurerelated analgesia (de Wied and Verbaten, 2001; Meagher et al., 2001). For each block, a set of 15 pictures was selected (picture sets 1 and 2). Care was given to ensure that both sets of pictures were equivalent in mean normative valence and arousal ratings for male subjects (picture set 1 : valence mean, 7.58; SD, 1.43; arousal mean, 6.56; SD, 2.01; picture set 2: valence mean, 7.38; SD, 1.39; arousal mean, 6.28; SD, 2.00). Stimuli consisted mainly of erotic (couples in erotic poses, nude females) and sports pictures. According to the motivational priming hypothesis by Lang and coworkers (1990), erotic pictures, having great motivational relevance, lead to strong appetitive system activation and arousal (Bradley et al., 2006). IAPS slide numbers for the two picture sets used were as follows: picture set 1: erotic: 4220, 4225, 4641, 4651, 4659, 4670, 4680; sports: $5621,5626,8080,8186,8190,8499,2071,8501$; picture set 2 : erotic: $4250,4599,4611,4652,4653,4658,4660,4695$; sports: 8170,8185 , $8200,8370,8496,2303,7330$. To control for position effects, the two picture sets were presented in counterbalanced order. Pictures in each set were presented in randomized order for $6 \mathrm{~s}$ followed by a white screen as interpicture interval that lasted for either 2 or $12 \mathrm{~s}$, resulting in a total set length of $180 \mathrm{~s}$. Participants were asked to attentively watch the pictures, let the pictures affect them, and to be open to imagining themselves as part of the shown situation when appropriate. A practice block consisting of two pictures was used to familiarize participants with the type of pictures they were about to see. Pictures were presented on a 19" monitor placed $\sim 70 \mathrm{~cm}$ away from participants.

Pain stimuli. Noxious heat stimuli were administered using a $30 \times 30$ mm Peltier device (TSA-II; Medoc) placed on the volar aspect of the nondominant forearm. Pain threshold was measured at the beginning of the experiment: volunteers were asked to stop the heat stimulus when they felt it turning from "hot" to "painful." For individual pain toler- ances, participants were asked to stop the increasingly painful stimulus at the point they could not stand it any longer. Pain threshold and pain tolerances were determined by calculating the average of three measurements starting at $35^{\circ} \mathrm{C}$ with a constant rise of temperature $\left(0.8^{\circ} \mathrm{C} / \mathrm{s}\right)$. To avoid physical injuries, the heating device was preprogrammed so that it stopped automatically at a maximum temperature of $52^{\circ} \mathrm{C}$. To diminish visual distraction, participants were asked to close their eyes during the full length of pain measurements. For pain tolerance measurements right after picture presentation, we asked participants "to remain in the affective state they experienced while looking at the pictures."

Autonomic reactivity. Skin conductance level (SCL) and startle blink electromyographic (EMG) response were measured with an eight-channel Varioport measurement system (Becker Meditec) and were saved on a compact flash card for off-line analyses. Sampling rate was set to $256 \mathrm{~Hz}$ for SCL and to $1024 \mathrm{~Hz}$ for EMG recordings. Skin conductance electrodes ( $\mathrm{Ag} / \mathrm{AgCl}, 5$ $\mathrm{mm}$ contact area diameter; Marquette Hellige Medical Systems) filled with lubricating jelly (SCL-Paste, $0.5 \% \mathrm{NaCl}$; Becker Meditec) were placed adjacently on the hypothenar eminence of the palm of the nondominant hand, which was cleansed in advance with distilled water. SCL raw data of each participant was amplified, dedrifted, rectified, and averaged throughout the picture-viewing periods in each block ( $180 \mathrm{~s})$. Startle blink responses were recorded from the orbicularis oculi muscle beneath the left eye, using two $4 \mathrm{~mm} \mathrm{Ag} / \mathrm{AgCl}$ electrodes placed $1.5 \mathrm{~cm}$ apart and a ground electrode placed on the mastoid bone following guidelines by Blumenthal et al. (2005). Startle responses were elicited by a $50 \mathrm{~ms}, 90 \mathrm{~dB}(\mathrm{~A})$ burst of white noise with instantaneous rise time presented binaurally over Philips SBCHP195 headphones. For each block, blink magnitudes of three startle probes presented during picture viewing were averaged; nonresponses were scored as zero magnitude blinks (13 of 132 blinks). Startle probes were presented $3000 \mathrm{~ms}$ after picture onset.

Subjective ratings. Subjects rated their pain intensity and unpleasantness on two consecutive visual analog scales (VASs) with the endpoints "no pain" and "worst pain experienced," and "neutral" and "extremely unpleasant," respectively. The VASs were presented on a monitor screen. Participants gave their ratings by mouse clicking the pursuant position on the VAS. The obtained ratings were then transformed into scores between 0 and 10 . To assess whether the induction of a positive affective state was effective, and to estimate whether naloxone altered hedonic responses to pleasant emotional stimuli, participants gave ratings regarding valence and arousal of the affective state they experienced on a computerized SAM (selfassessment manikin questionnaire). The formulated questions were, for valence: "How pleasant or unpleasant were your feelings while watching the pictures?" and, for arousal, "How arousing were your feelings while watching the pictures?" The SAM consisted of two sets of five pictographs depicting different levels of affective valence and arousal (Lang, 1980). Subjects were asked to click with the cursor on or between the figures. For each dimension, ratings between 1 and 9 were recorded. Ratings were scored such that 9 represented a high rating on each dimension. The manipulation check to verify emotional induction was conducted after the pain ratings to minimize possible demand or expectation effects (Meagher et al., 2001). To assess the influence of naloxone on mood, the Mehrdimensionaler Befindlichkeitsfragebogen (MDBF; Multidimensional Mood State Questionnaire) (Steyer et al., 1997) was used at the start and at the end of the experiment. It included adjectives for the dimensions "feeling well versus not well," "feeling alert versus tired," and "feeling calm versus aroused." For each dimension, ratings between 1 and 5 were recorded. Ratings were scored such that 5 represented a high rating on each dimension (e.g., well, alert, and aroused). The two parallel versions of the questionnaire were given to participants in counterbalanced order. At the end of the experimental session, participants answered whether they believed having received naloxone or saline by clicking a pursuant check box on the monitor.

Experimental procedure. At the beginning of each experimental session, participants were screened for medical problems (self-report) and were told that the main aim of the study was evaluating the impact of emotional pictures on the individual affective state. To prevent participants from focusing on the painful stimuli, and to focus their attention on pleasure induction, the occurrence of noxious heat stimuli was mentioned but not as a principal study goal. After determining the weight of 
volunteers and the insertion of an intravenous catheter, participants were seated in front of a monitor in a dimly lit room. The experimenter affixed the thermode and the electrodes for autonomic reaction measurements and asked participants to follow the instructions presented on the computer screen (SuperLab 4.0). The experiment was divided into two blocks (Fig. 1). In each block, one of the two picture sets was presented. Right before and after picture presentation, pain tolerance succeeded by subjective pain ratings (VAS) was assessed. At the end of each block, participants rated the affective state they had experienced while watching the pictures (SAM). Right before block 1 , and immediately after block 2 , mood ratings were assessed (MDBF). In between blocks, naloxone or saline was administered. Special care was given so that participants did not feel any pain or worry about the procedure. While waiting for the onset of naloxone effects after intravenous administration ( $\sim 2 \mathrm{~min})$ and to distract subjects from the just experienced drug administration, a short ( $3 \mathrm{~min}$ ) geometrical task was displayed on the monitor (meaningless geometric figure pairs had to be judged for similarity).

The experiments were performed according to a randomized doubleblind design. For safety reasons (potential unforeseen side-effects of naloxone), the experimenter and the medical doctor stayed behind a partition in the same room. To control for confounding factors associated with circadian variations and the experimenter's presence, all participants were tested in the afternoon and by the same experimenter. At the end of an experimental session (total duration, $\sim 70 \mathrm{~min}$ ), volunteers were debriefed about the experimental aims and received a monetary compensation for their participation in the study.

Data analysis. For pain tolerance measurements, pain, and emotional ratings, repeated-measures ANOVAs were performed. Within-subject factors were block (block 1: before injection vs block 2: after injection) and time (before picture viewing vs after picture viewing), with group (naloxone vs control) as a between-subject factor. $p$ values in the ANOVAs and $t$ tests were corrected using Greenhouse-Geisser and Bonferroni correction, respectively. Post hoc comparisons were performed using two-tailed Student's paired $t$ tests. Correlations between skin conductance levels were calculated separately for both groups using Pearson's correlation coefficient. In the analysis of subjective pain ratings, Grubb's test for outliers uncovered one outlier, which was therefore excluded from VAS analyses. Significance level was set at $p<0.05$ for all statistical calculations.

\section{Results}

\section{Expectation}

Seventy-seven percent of the study participants believed they had received saline. Two participants who thought they had received naloxone were in the naloxone group and the other three were in the control group.

\section{Pain tolerance}

The repeated-measures ANOVA with the factors group, block, and time was significant for the factor time; after picture viewing tolerances were higher $\left(F_{(1,20)}=29.61, p=0.000\right)$. The factor block was also significant; tolerances were lower in block $2\left(F_{(1,20)}=16.82, p=0.001\right)$. The block-by-time interaction was significant as well $\left(F_{(1,20)}=18.54, p=0.000\right)$ (Fig. $2)$. Post hoc $t$ tests confirmed that pain tolerance increased significantly after picture viewing for both blocks (block 1: $t_{(21)}=-2.94, p=0.008$; block 2: $\left.t_{(21)}=-5.67, p=0.000\right)$, but decreased after injection [(block 1 pre-picture viewing) (block 2 pre-picture viewing); $\left.t_{(21)}=4.70, p=0.000\right]$. No

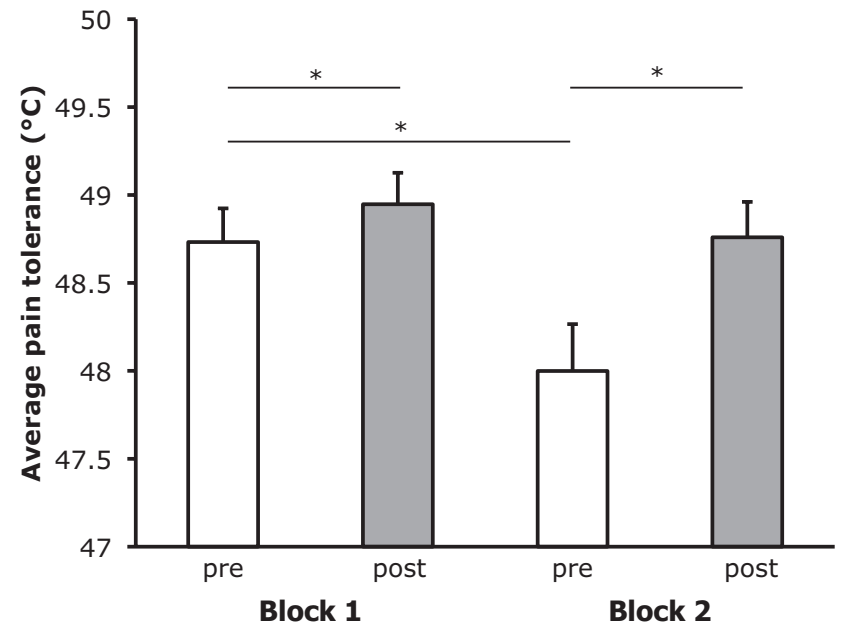

Figure 2. Mean levels of heat pain tolerance $\left({ }^{\circ} \mathrm{C}\right)$ before (pre) and after (post) picture viewing in block 1 (before drug administration) and block 2 (after drug administration). Pain tolerance increased significantly after picture viewing in both blocks but decreased after drug administration only. Asterisks indicate significant, post hoc comparisons $(p<0.05)$. Bars depict average values and SES.

other effects were significant, suggesting that naloxone influenced neither pain tolerance nor pleasure-related analgesia.

\section{Pain ratings}

For pain intensity, a significant effect found for the factor block was that pain intensity ratings were higher after injection $\left(F_{(1,19)}=5.35\right.$, $p=0.032$ ). Both scales showed a significant block-by-group interaction (intensity: $F_{(1,19)}=4.52, p=0.047$; unpleasantness: $F_{(1,19)}=$ $4.31, p=0.050)$. Post hoc $t$ tests uncovered that the naloxone group gave higher pain ratings after injection (intensity: $t_{(10)}=-3.48, p=$ 0.006; unpleasantness: $\left.t_{(10)}=-2.57, p=0.028\right)$, whereas control group ratings did not change significantly (intensity: $t_{(9)}=-0.120$, $p=0.91$; unpleasantness: $t_{(9)}=0.122, p=0.91$ ) (Fig. 3). No other effects were seen.

\section{Picture ratings}

Data for blocks 1 and 2 confirm that the picture sets induced the targeted pleasant affective state (mean valence, $>7.5$; mean arousal, >5.5). For SAM valence, we found a significant effect for 
A

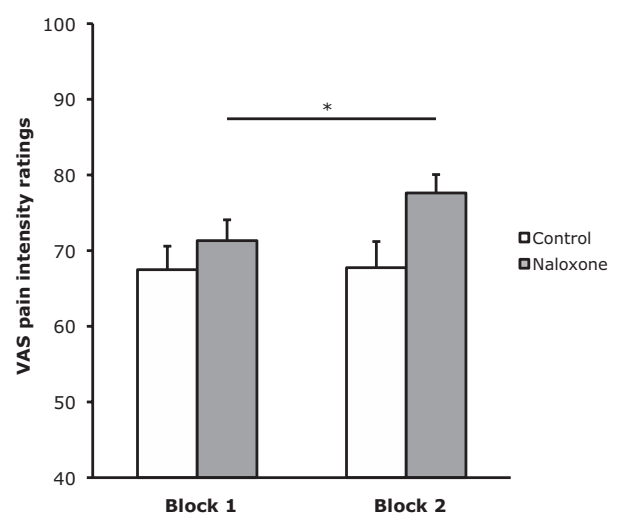

B

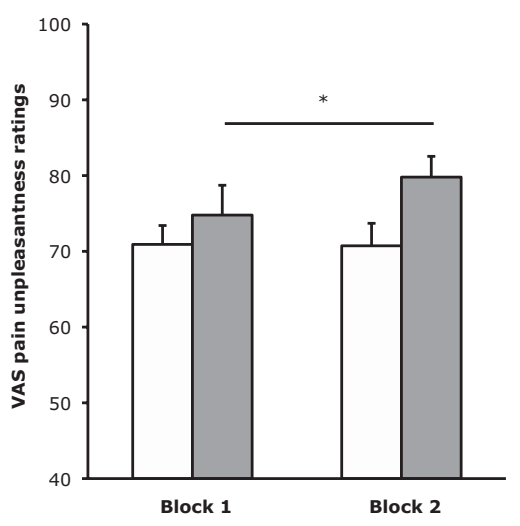

Figure 3. $\boldsymbol{A}, \boldsymbol{B}$, Mean VAS pain-intensity ratings $(\boldsymbol{A})$ and mean VAS pain-unpleasantness ratings $(\boldsymbol{B})$ in block 1 (before drug administration) and block 2 (after drug administration). VAS ratings increased in block 2 significantly but only in the naloxone group. Asterisks indicate significant, post hoc comparisons $(p<0.05)$. Bars depict average values and SEs.

sponses to external emotional stimuli, such as sweet taste (Berridge, 2003), IAPS pictures (Gospic et al., 2008), and monetary reward (Petrovic et al., 2008), were shown to be modulated by opioids. In our study, mood and subjective ratings of experienced affective states during pleasant-picture viewing were not significantly influenced by naloxone. Corroboratively, skin conductance responses, consistently shown to covary with arousal judgments (Lang et al., 1990), and the magnitudes of acoustically elicited startle eye blinks, a reliable marker for the valence of an affective state (Lang et al., 1990), remained unchanged. Current hypotheses suggest that analgesia induced by viewing emotionally loaded pictures grounds on effects from changes in affective state and covariate, hardly dissociable attentional processes (Villemure and Bushnell, 2002). Since subjective and autonomic reac-

the factor block, but not for arousal ratings (valence: $F_{(1,20)}=$ $6.43, p=0.02$; arousal: $\left.F_{(1,20)}=0.030, p=0.87\right)$. The valence ratings for the affective state decreased in block 2 , yet still mirrored highly pleasant states (mean, >6.8). We found no blockby-group interaction for either scale, suggesting that naloxone did not alter hedonic responses to pleasant visual stimuli. Affective state ratings for block 1 did not differ depending on picture set 1 , indicating that the emotional impact of both picture sets was equivalent (independent samples $t$ test for valence and arousal, $p>0.27$ ).

\section{Autonomic reactivity}

Averaged SCLs throughout the picture viewing periods were not significant for the factor block, nor the block-by-group interaction (both $p>0.46$ ). Conversely, correlation analyses between skin conductance levels in block 1 and block 2 were significant in both groups (control: $\rho=0.471, p<0.001$; naloxone: $\rho=0.484$, $p<0.001$ ), confirming that hedonic response, in terms of SCL, was not affected by naloxone. Analogously, averaged startle magnitudes during pleasure induction were not significantly altered by blockade of endorphinergic activity (block and block-bygroup, $p>0.13)$.

\section{Mood}

The factor scale was significant $\left(F_{(1,20)}=3.52, p=0.050\right)$, whereby post hoc $t$ test of scale ratings did not survive Bonferroni corrections, suggesting that ratings for "feeling well versus not well," "feeling alert versus tired," and "feeling calm versus aroused" did not differ. Moreover, the block-by-time and block-by-group interactions were not significant (both $p>0.19$ ), indicating that mood was constant during the experiment, uninfluenced by naloxone.

\section{Discussion}

Our study examined the contribution of endogenous opioids in emotional pain modulation. We hypothesized that enhanced opioidergic neurotransmission during positive affective states contributes to pleasure-related analgesia. Contrary to our expectations, hedonic response to pleasant visual stimuli and altered pain tolerances were insensitive to naloxone. Subjective pain intensity and unpleasantness ratings increased after naloxone injection.

Positive affective states are associated with enhanced opioidergic activity (Boecker et al., 2008; Koepp et al., 2009) and negative states with its deactivation (Zubieta et al., 2003). Also, the hedonic re- tions to pleasure induction and overall mood neither differed between groups nor changed during the experiment, we suggest that the degree of attention was equivalent among participants.

Many studies have identified a major role of the endogenous opioid system in pain modulation by reversing its effects with naloxone (Gracely et al., 1983; Amanzio and Benedetti, 1999; Eippert et al., 2008) and using molecular imaging techniques (Zubieta et al., 2005; Scott et al., 2008). Our findings show that pleasure-related analgesia, measured as an increase in pain tolerance, was insensitive to naloxone injection. After substance administration, we found a substance-unspecific decrease in pain tolerance. It is probable and even likely that the procedure of drug administration (pressure in the vein) was responsible for these results. In line with previous findings on the effects of naloxone on heat-pain measurements, the increased level of subjective pain ratings of intensity and unpleasantness was substance specific (Borras et al., 2004). This result is highly appealing, as it suggests that $\mu$-opioidergic neurotransmission is involved in the subjective response to heat pain. Because pain tolerances after pleasure induction were not attenuated by naloxone, it can be assumed that a major involvement of opioid-insensitive inhibitory systems is at work here. Studies on stress-induced analgesia and on placebo analgesia have similarly proposed the existence of opioid-sensitive and opioid-insensitive descending modulatory systems (Amanzio and Benedetti, 1999; Flor et al., 2002; Ford and Finn, 2008). Several neurotransmitter systems, including dopaminergic, serotonergic, cannabinergic, and monoaminergic, have been shown to play a role in endogenous pain inhibition, but there is still a need for research on these systems (Millan, 2002). Although highly speculative, we consider dopamine signaling as a potential candidate able to preserve hedonic processing in the absence of opioid mediation. Along this line of reasoning, a recent review of the literature has shown a key role of dopamine on pain perception in humans, suggesting its involvement in endogenous pain modulation systems (Potvin et al., 2009). In addition, pleasure and reward expectation have been associated with increased phasic dopamine signaling (Schultz, 2010). Even if the precise role of dopamine in pain and reward is far from unequivocal (Leknes and Tracey, 2008), and its function varies at different time courses (Schultz, 2007), some recent evidence suggests a possible opioid-independent dopaminergic me- 
diation of hedonic processes (Scott et al., 2008). It is important to also consider the potential role of endocannabinoids for the present results, as they have been related to nondrug rewarding behaviors (Fattore et al., 2010) and in analgesia (Guindon and Hohmann, 2009). Notably, substantial and complex interactions between endocannabinoid systems and opioids in nociception (Welch, 2009) and dopamine in the processing of motivationally salient information have been described (Laviolette and Grace, 2006). But the interactions are complex and future studies will be needed to further elucidate a separate or cojoint action of these systems in the processing of reward-related analgesia. From a homeostatic perspective, the fact that reversal of endogenous $\mu$-opioid neurotransmission did not significantly alter-at least at the behavioral level-hedonic processing and pain inhibition is comprehensible. The notion that both of them are maintained by different complementing, interacting, and overlapping neural and chemical modulatory circuits, quickly equilibrating external disturbances, seems quite compelling if affective processes are conceptualized as action dispositions able to regulate and optimize an individual's response to motivationally relevant stimuli (Lang et al., 1990).

Three methodological caveats limit the interpretation of our results. First, we measured effects of naloxone on hedonic and pain responses $3 \mathrm{~min}$ after bolus administration. We decided to use a short measurement window, compared with other studies, since naloxone is well known for its rapid onset of action, rate of elimination, and distribution being administered in clinical settings in 2-3 min intervals (Ngai et al., 1976; Goldfrank et al., 1986). Although this methodological limitation does not allow for verification of complete receptor blockage by the time of measurement, the significant effects of naloxone on subjective pain ratings support at least a partial blockage of endogenous painmodulatory mechanisms. Bearing this in mind, it should be expected that having a peak blockage of opioid receptors by using a longer time window would result in even stronger effects. Second, we observed a decrease of subjective valence ratings in block 2 that was group independent and most probably due to habituation effects. This might have resulted in a floor effect preventing naloxone from producing any further changes in valence and arousal. One could argue that viewing pleasant photographs, mostly erotic in nature, within an experimental setting might not have changed the basal level of endogenous opioids, leaving blockage of $\mu$-opioid receptors without any consequences. However, this would imply a negligible role of $\mu$-opioidergic neurotransmission in hedonic processing since participants clearly experienced positive affective states. Alternative interpretations are possible. It might be that with our experimental design, changes in opioid neurotransmission in core processes of positive affective reaction might have happened, but at levels far too low to be detectable at behavioral levels. Future studies using stronger pleasure-inducing methods, and thus presumably involving pronounced endogenous opioid release, might reveal larger antagonizing effects. The inclusion of neutral affective stimuli in these experimental designs will likely improve the explanatory power of the reported findings. Third, we measured a small sample size, which advises for a cautious interpretation of our results. However, we firmly believe that this study provides preliminary yet clear evidence for opioid-sensitive and opioid-insensitive components of affective regulation and modulation of pain experiences. Future studies using more sensitive measurement techniques focusing on molecular endogenous opioid peptides may also contribute to deepen our understanding of the effects of opioid-insensitive components of affective regulation. Undoubt- edly, the further understanding of the neurobiological underpinnings of pleasure-related analgesia will be of great benefit for the clinical management of pain.

\section{References}

Amanzio M, Benedetti F (1999) Neuropharmacological dissection of placebo analgesia: expectation-activated opioid systems versus conditioningactivated specific subsystems. J Neurosci 19:484-494.

Becerra L, Breiter HC, Wise R, Gonzalez RG, Borsook D (2001) Reward circuitry activation by noxious thermal stimuli. Neuron 32:927-946.

Benedetti F, Mayberg HS, Wager TD, Stohler CS, Zubieta JK (2005) Neurobiological mechanisms of the placebo effect. J Neurosci 25:10390-10402. Berridge KC (2003) Pleasures of the brain. Brain Cogn 52:106-128.

Blumenthal TD, Cuthbert BN, Filion DL, Hackley S, Lipp OV, van Boxtel A (2005) Committee report: guidelines for human startle eyeblink electromyographic studies. Psychophysiology 42:1-15.

Boecker H, Sprenger T, Spilker ME, Henriksen G, Koppenhoefer M, Wagner KJ, Valet M, Berthele A, Tolle TR (2008) The runner's high: opioidergic mechanisms in the human brain. Cereb Cortex 18:2523-2531.

Borras MC, Becerra L, Ploghaus A, Gostic JM, DaSilva A, Gonzalez RG, Borsook D (2004) fMRI measurement of CNS responses to naloxone infusion and subsequent mild noxious thermal stimuli in healthy volunteers. J Neurophysiol 91:2723-2733.

Bradley MM, Codispoti M, Lang PJ (2006) A multi-process account of startle modulation during affective perception. Psychophysiology 43:486-497.

Burgdorf J, Panksepp J (2006) The neurobiology of positive emotions. Neurosci Biobehav Rev 30:173-187.

Chapman LJ, Chapman JP (1987) The measurement of handedness. Brain Cogn 6:175-183.

Colloca L, Benedetti F (2005) Placebos and painkillers: is mind as real as matter? Nat Rev Neurosci 6:545-552.

de Wied M, Verbaten MN (2001) Affective pictures processing, attention, and pain tolerance. Pain 90:163-172.

Eippert F, Bingel U, Schoell E, Yacubian J, Büchel C (2008) Blockade of endogenous opioid neurotransmission enhances acquisition of conditioned fear in humans. J Neurosci 28:5465-5472.

Enck P, Benedetti F, Schedlowski M (2008) New insights into the placebo and nocebo responses. Neuron 59:195-206.

Fattore L, Melis M, Fadda P, Pistis M, Fratta W (2010) The endocannabinoid system and nondrug rewarding behaviours. Exp Neurol 224:23-36.

Fields H (2004) State-dependent opioid control of pain. Nat Rev Neurosci 5:565 $\gamma$ Çô575.

Fields HL (2007) Understanding how opioids contribute to reward and analgesia. Reg Anesth Pain Med 32:242-246.

Flor H, Birbaumer N, Schulz R, Grüsser SM, Mucha RF (2002) Pavlovian conditioning of opioid and nonopioid pain inhibitory mechanisms in humans. Eur J Pain 6:395-402.

Ford GK, Finn DP (2008) Clinical correlates of stress-induced analgesia: evidence from pharmacological studies. Pain 140:3-7.

Goldfrank L, Weisman RS, Errick JK, Lo MW (1986) A dosing nomogram for continuous infusion intravenous naloxone. Ann Emerg Med 15:566-570.

Gospic K, Gunnarsson T, Fransson P, Ingvar M, Lindefors N, Petrovic P (2008) Emotional perception modulated by an opioid and a cholecystokinin agonist. Psychopharmacology (Berl) 197:295-307.

Gracely RH, Dubner R, Wolskee PJ, Deeter WR (1983) Placebo and naloxone can alter post-surgical pain by separate mechanisms. Nature 306:264-265.

Guindon J, Hohmann AG (2009) The endocannabinoid system and pain. CNS Neurol Disord Drug Targets 8:403-421.

Koepp MJ, Hammers A, Lawrence AD, Asselin MC, Grasby PM, Bench CJ (2009) Evidence for endogenous opioid release in the amygdala during positive emotion. Neuroimage 44:252 $\gamma$ Çô256.

Kut E, Schaffner N, Wittwer A, Candia V, Brockmann M, Storck C, Folkers G (2007) Changes in self-perceived role identity modulate pain perception. Pain 131:191-201.

Lang PJ (1980) Behavioral treatment and bio-behavioral assessment: computer applications. In: Technology in mental health care delivery system (Sidowski JB, Johnson JH, Williams EA, eds), pp 119-137. Norwood, NJ: Ablex. 
Lang PJ, Bradley MM, Cuthbert BN (1990) Emotion, attention, and the startle reflex. Psychol Rev 97:377-395.

Lang PJ, Bradley MM, Cuthbert BN (2004) International Affective Picture System (IAPS): affective ratings of pictures and instruction manual. Technical report A-6. Gainesville, FL: University of Florida.

Laviolette SR, Grace AA (2006) The roles of cannabinoid and dopamine receptor systems in neural emotional learning circuits: implications for schizophrenia and addiction. Cell Mol Life Sci 63:1597-1613.

Leknes S, Tracey I (2008) A common neurobiology for pain and pleasure. Nat Rev Neurosci 9:314 $\gamma$ Çô320.

Lewkowski MD, Young SN, Ghosh S, Ditto B (2008) Effects of opioid blockade on the modulation of pain and mood by sweet taste and blood pressure in young adults. Pain 135:75-81.

Meagher MW, Arnau RC, Rhudy JL (2001) Pain and emotion: effects of affective picture modulation. Psychosom Med 63:79-90.

Millan MJ (2002) Descending control of pain. Prog Neurobiol 66:355-474.

Ngai SH, Berkowitz BA, Yang JC, Hempstead J, Spector S (1976) Pharmacokinetics of naloxone in rats and in man: basis for its potency and short duration of action. Anesthesiology 44:398-401.

Panksepp J (2003) Feeling the pain of social loss. Science 302:237-239.

Peciña S (2008) Opioid reward 'liking' and 'wanting' in the nucleus accumbens. Physiol Behav 94:675-680.

Petrovic P, Kalso E, Petersson KM, Ingvar M (2002) Placebo and opioid analgesia: imaging a shared neuronal network. Science 295:1737-1740.

Petrovic P, Pleger B, Seymour B, Klöppel S, De Martino B, Critchley H, Dolan RJ (2008) Blocking central opiate function modulates hedonic impact and anterior cingulate response to rewards and losses. J Neurosci 28:10509-10516.

Potvin S, Grignon S, Marchand S (2009) Human evidence of a supra-spinal modulating role of dopamine on pain perception. Synapse 63:390-402.

Rainville P, Bao QV, Chrétien P (2005) Pain-related emotions modulate experimental pain perception and autonomic responses. Pain 118:306-318.

Roy M, Piché M, Chen JI, Peretz I, Rainville P (2009) Cerebral and spinal modulation of pain by emotions. Proc Natl Acad Sci U S A 106:20900-20905.

Rozin P, Schiller D (1980) The nature and acquisition of a preference for chili pepper by humans. Motiv Emot 4:77-101.

Schaffner N, Wittwer A, Kut E, Folkers G, Benninger DH, Candia V (2008)
Heat pain threshold and tolerance show no left-right perceptual differences at complementary sites of the human forearm. Neurosci Lett 440:309-313.

Schultz W (2007) Multiple dopamine functions at different time courses. Annu Rev Neurosci 30:259-288.

Schultz W (2010) Multiple functions of dopamine neurons. F1000 Biol Rep 2.pii:2.

Scott DJ, Stohler CS, Egnatuk CM, Wang H, Koeppe RA, Zubieta JK (2008) Placebo and nocebo effects are defined by opposite opioid and dopaminergic responses. Arch Gen Psychiatry 65:220-231.

Sprenger T, Valet M, Boecker H, Henriksen G, Spilker ME, Willoch F, Wagner KJ, Wester HJ, Tölle TR (2006) Opioidergic activation in the medial pain system after heat pain. Pain 122:63-67.

Steyer R, Schwenkmezger P, Notz P, Eid M (1997) Der Mehrdimensionale Befindlichkeitsfragebogen (MDBF). Göttingen: Hogrefe.

Tracey I, Mantyh PW (2007) The cerebral signature for pain perception and its modulation. Neuron 55:377-391.

Villemure C, Bushnell MC (2002) Cognitive modulation of pain: how do attention and emotion influence pain processing? Pain 95:195-199.

Villemure C, Bushnell MC (2009) Mood influences supraspinal pain processing separately from attention. J Neurosci 29:705-715.

Welch SP (2009) Interaction of the cannabinoid and opioid systems in the modulation of nociception. Int Rev Psychiatry 21:143-151.

Wiech K, Ploner M, Tracey I (2008) Neurocognitive aspects of pain perception. Trends Cogn Sci 12:306 $\gamma$ Çô313.

Yarnitsky D, Sprecher E, Zaslansky R, Hemli JA (1995) Heat pain thresholds: normative data and repeatability. Pain 60:329-332.

Zubieta JK, Smith YR, Bueller JA, Xu Y, Kilbourn MR, Jewett DM, Meyer CR, Koeppe RA, Stohler CS (2001) Regional mu opioid receptor regulation of sensory and affective dimensions of pain. Science 293:311-315.

Zubieta JK, Ketter TA, Bueller JA, Xu Y, Kilbourn MR, Young EA, Koeppe RA (2003) Regulation of human affective responses by anterior cingulate and limbic mu-opioid neurotransmission. Arch Gen Psychiatry 60:1145-1153.

Zubieta JK, Bueller JA, Jackson LR, Scott DJ, Xu Y, Koeppe RA, Nichols TE, Stohler CS (2005) Placebo effects mediated by endogenous opioid activity on mu-opioid receptors. J Neurosci 25:7754-7762. 